\title{
Characteristics of dilatational infrasonic pulses accompanying low-frequency earthquakes at Miyakejima Volcano, Japan
}

\author{
Yoshiaki Fujiwara ${ }^{1 *}$, Hitoshi Yamasato ${ }^{2}$, Toshiki Shimbori ${ }^{3}$ and Takayuki Sakai ${ }^{1}$
}

\begin{abstract}
Since the caldera-forming eruption of Miyakejima Volcano in 2000, low-frequency (LF) earthquakes have occurred frequently beneath the caldera. Some of these LF earthquakes are accompanied by emergent infrasonic pulses that start with dilatational phases and may be accompanied by the eruption of small amounts of ash. The estimated source locations of both the LF earthquakes and the infrasonic signals are within the vent at shallow depth. Moreover, the maximum seismic amplitude roughly correlates with the maximum amplitude of the infrasonic pulses. From these observations, we hypothesized that the infrasonic waves were excited by partial subsidence within the vent associated with the LF earthquakes. To verify our hypothesis, we used the infrasonic data to estimate the volumetric change due to the partial subsidence associated with each LF earthquake. The results showed that partial subsidence in the vent can well explain the generation of infrasonic waves.
\end{abstract}

\section{Background}

Miyakejima Island is one of the Izu Islands in the northern Izu-Bonin volcanic arc. It is about $200 \mathrm{~km} \mathrm{SSW} \mathrm{of} \mathrm{Tokyo}$ and is the site of one of the most active stratovolcanoes in Japan. The volcano is characterized by repeated, persistent volcanic activity with episodic basaltic fissure eruptions on the mountain's flank (Tsukui and Suzuki 1998; Tsukui et al. 2001). The latest large eruption at Miyakejima occurred in August 2000. Earthquake swarms migrating around Miyakejima Island in June 2000 were linked to the movement of magma (Uhira et al. 2005), which resulted in the formation of a collapse caldera $1.6 \mathrm{~km}$ in diameter and $450 \mathrm{~m}$ deep at the summit in July 2000 (Nakada et al. 2005). After three large eruptions in August 2000, large amounts of volcanic gas, especially $\mathrm{SO}_{2}$, began to be emitted from the vent, which is near its southern margin within the caldera. These emissions are ongoing (Kazahaya et al. 2004).

Although the seismicity at Miyakejima was very low before the activity began in 2000, low-frequency (LF) microearthquake swarms have occurred frequently beneath the summit since the formation of the caldera.

\footnotetext{
* Correspondence: y_fujiwara@met.kishou.go.jp

'Japan Meteorological Agency, 1-3-4 Otemachi, Chiyoda-ku, Tokyo 100-8122, Japan

Full list of author information is available at the end of the article
}

Such swarms continue to be observed every few months, sometimes following a minor eruption. The magnitude of the LF earthquakes is sometimes more than 2 in JMA scale, which is larger than ordinary LF earthquakes at other active volcanoes. Furthermore, the LF earthquakes are often accompanied by small infrasonic pulses, and the infrasonic signals are characterized by a dilatational first phase.

Numerous studies have investigated infrasonic signals at active volcanoes: for example, at Unzendake (Yamasato 1997, 1998), Usu (Yamasato et al. 2002), Tokachi (Okada et al. 1990), and Sakurajima (Ishihara and Iguchi 1989; Kamo et al. 1989; Sakai et al. 1996) in Japan. However, infrasonic signals with dilatational first phases have not been reported previously. The aim of our study was to examine the characteristics of the infrasonic signals at Miyakejima and to discuss their mechanism of origin.

\section{Methods}

Data

The Japan Meteorological Agency (JMA) has installed a seismic and infrasonic microphone (ACO; Type $3348+7144)$ network at Miyakejima (Figures 1 and 2). Each station is equipped with a short-period $(1 \mathrm{~Hz})$, three-component (north, east, vertical) seismometer 


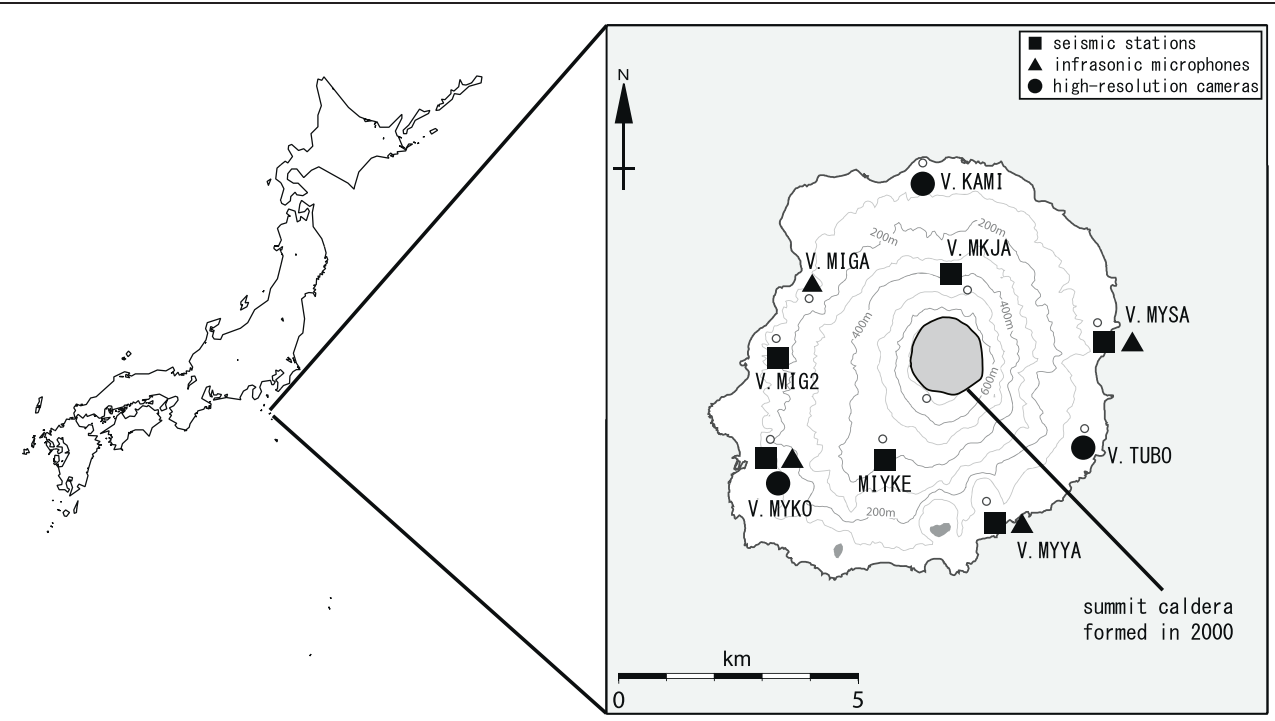

Figure 1 Locations of seismic and infrasonic stations of the Japan Meteorological Agency at Miyakejima Volcano, Japan. Solid squares represent three-component short-period $(1 \mathrm{~Hz})$ seismic stations. Solid triangles indicate the locations of infrasonic microphones. Solid circles are the locations of high-resolution cameras which are able to visualize the volcano even at night. Shaded area indicates the summit caldera that formed in 2000.

and/or an infrasonic microphone. The phase response has a maximum phase shift of $2.88 \mathrm{rad}$ at $0.1 \mathrm{~Hz}$, as shown in Figure 3b. The data are sampled continuously at a frequency of $100 \mathrm{~Hz}$ and transmitted to the Tokyo Volcano Observation and Information Center of JMA, where they are routinely monitored and continuously recorded onto hard disks.
We also installed a temporary infrasonic microphone in October 2005 at the margin of the caldera (V.MYCR in Figure 1) so that we could compare the waveform characteristics at that site with those at other stations for precise determination of the infrasonic sources.

The responses of $\mathrm{ACO}$ are checked by comparing with BK (Brüel \& Kjær; Type $2690+4193$ ) (see Figure 3).

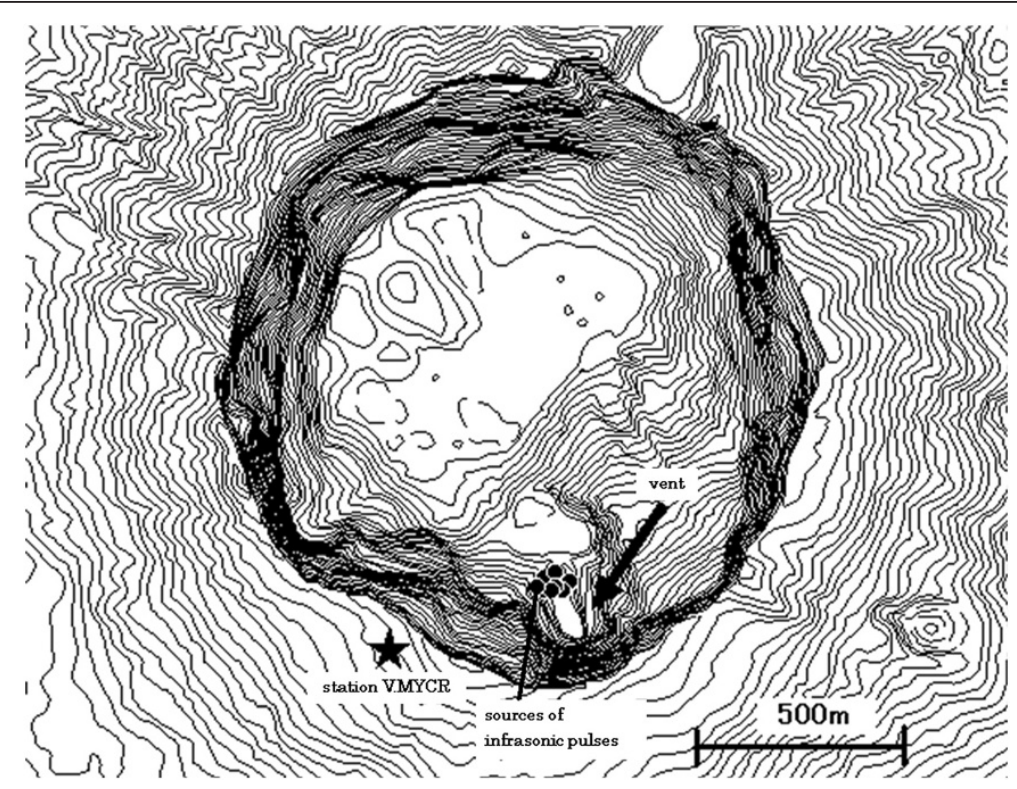

Figure 2 Detailed topographic map of the summit caldera of Miyakejima Volcano. It is based on a 1:25,000 topographical map by the Geographical Survey Institute. The star shows the location of station V.MYCR, and the arrow indicates the vent. The solid dots represent calculated source locations of infrasonic pulses accompanying relatively large LF events, which were calculated using data from at least our stations, one of which was V.MYCR. 

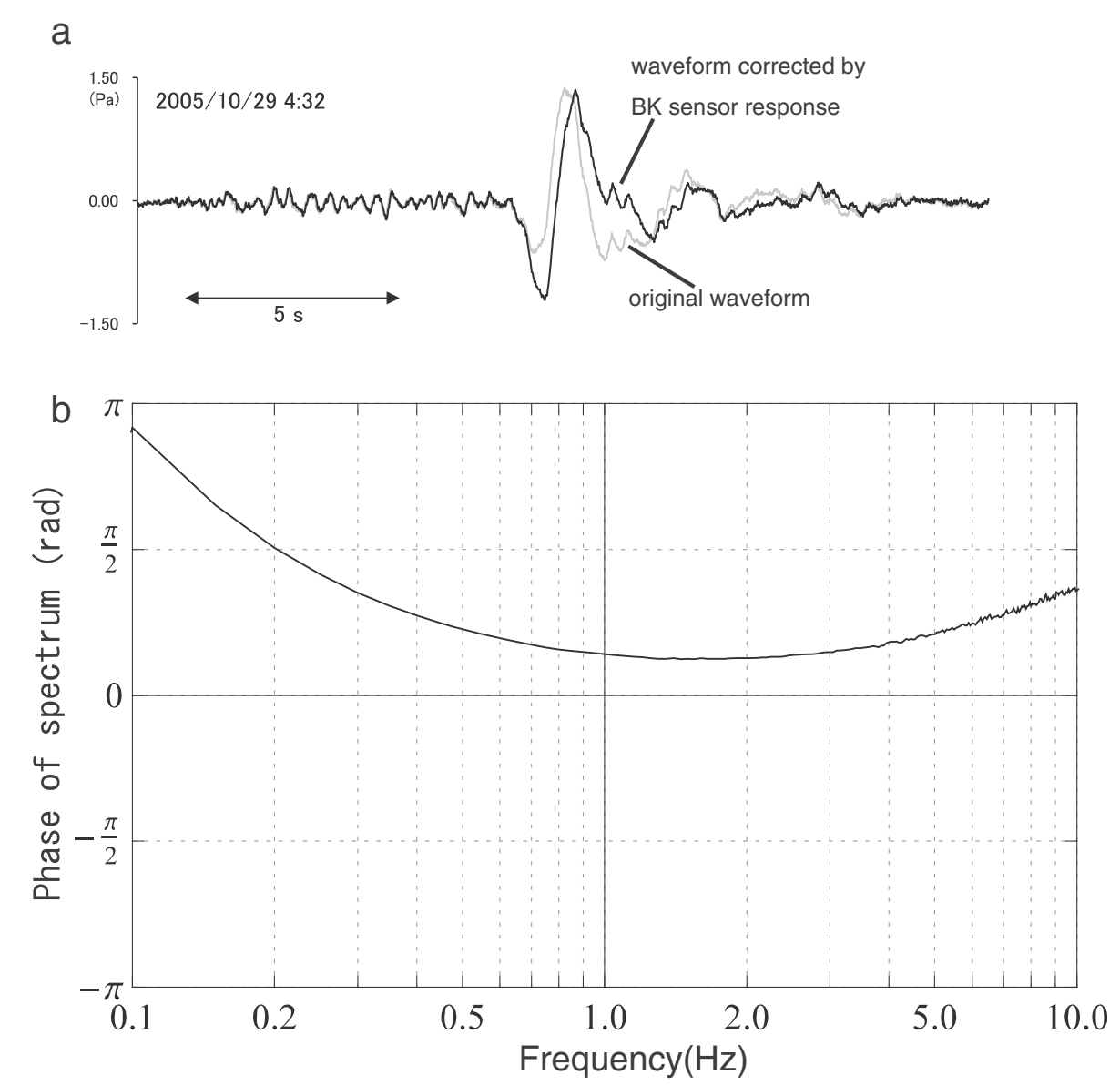

Figure 3 Infrasonic record and cross spectrum curve. (a) Example of infrasonic record obtained at station V.MIGA. Thin gray and black lines denote the original and corrected waveform by the response of the BK sensor, respectively (see the 'Data' section for details). (b) Cross spectrum curve of phase response of the corrected waveform for the original one using statistical data by BK sensor. The faster phase shift of ACO for BK sensor is identified.

Shimbori et al. (2013) concluded that the observed infrasonic waves by individual sensors are identical by correcting the phase characteristics among these instruments, which indicates that the observed maximum amplitudes and periods have no large difference within the order of magnitude. Therefore, using the value by ACO does not affect the estimation of volumetric change.

In addition to this network, high-resolution cameras, which are able to visualize the volcano even at night, were installed at three sites for detection of volcanic ash (Figure 1).

\section{Classification of seismic events beneath the vent}

Since the eruptions in 2000, we have observed three types of volcanic earthquakes at Miyakejima, according to the classification proposed by Yamasato et al. (2008) (Figure 4). The entire dataset was initially categorized on the basis of the time-domain seismograms.
High-frequency (HF) earthquakes, which show clear $P$ - and $S$-phases and are considered to have a doublecouple mechanism, consist of HF components of more than several Hertz, whereas intermediate-frequency (MF) and LF earthquakes are characterized by a weak signal onset with a peak frequency near $5 \mathrm{~Hz}$ or 3 to $5 \mathrm{~Hz}$, respectively. MF earthquake swarms sometimes precede LF earthquakes (Figure 4), but we are presently unable to determine accurately how MF earthquakes are generated. Occasionally, LF earthquakes are accompanied by small-amplitude infrasonic pulses (see Figure 4) and sometimes by emissions of a small amount of ash. The amplitudes of infrasonic pulses accompanying LF earthquakes with a magnitude of at least 1.0 occurring since October 2005, when station V.MYCR was installed, are presented in Table 1.

The numbers of LF and HF earthquakes at Miyakejima per day are shown in Figure 5. HF and LF earthquakes occurred with notable frequency from 2001 to late 2002, but activity gradually became less intense from 
(a)

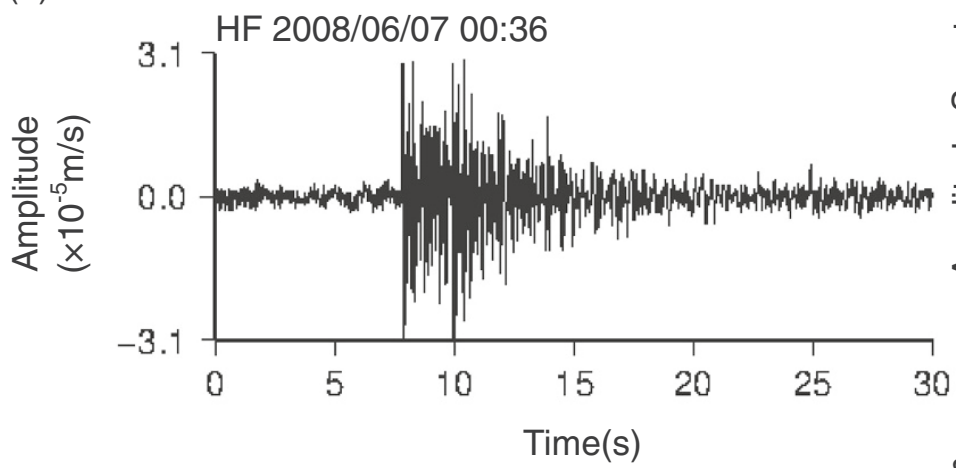

(b)

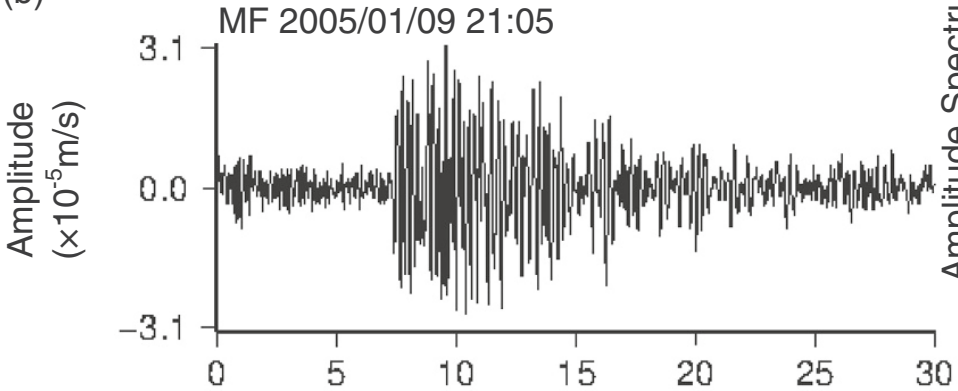

Time(s)

(c)

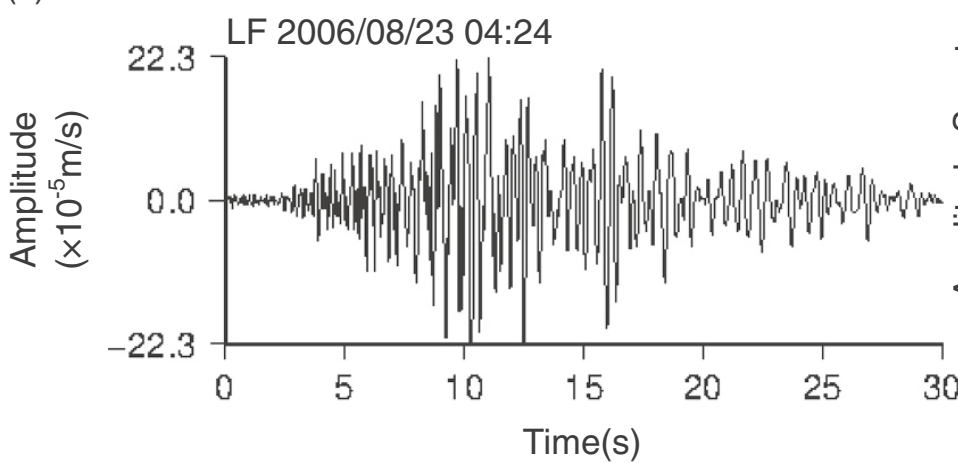

(d)
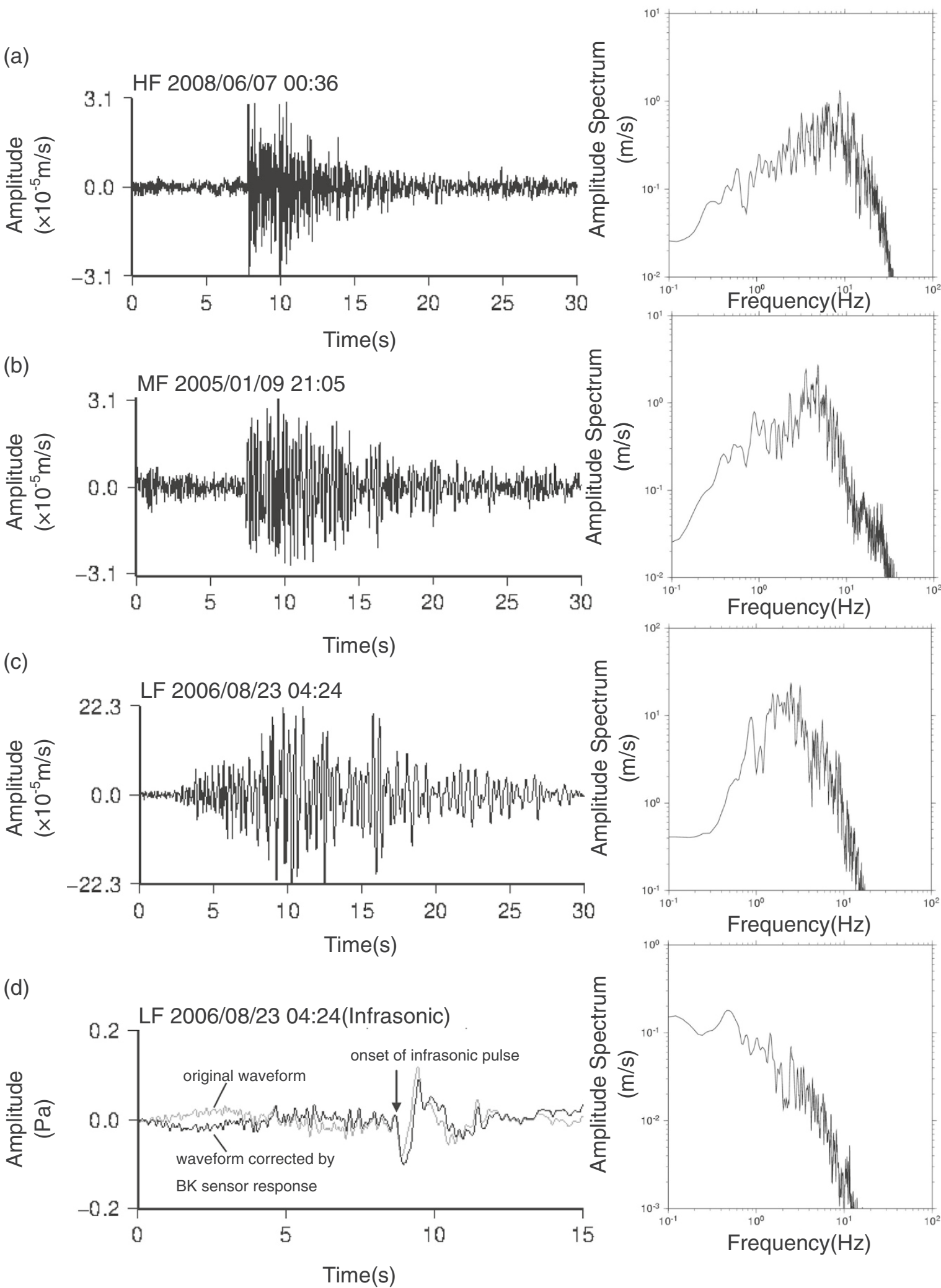

Figure 4 Vertical-component seismograms (a-c) of earthquakes observed at station V.MKJA and infrasonic record obtained at station V.MYYA (d). High-frequency noise caused by ground motion is superimposed on the infrasonic records before the onset of the infrasonic pulse, which is shown by the arrow. 
Table 1 Low-frequency earthquakes observed at Miyakejima Volcano with seismic magnitude of $>1.0$ and a clear dilatational infrasonic pulse

\begin{tabular}{|c|c|c|c|c|c|c|c|c|c|c|c|c|c|}
\hline \multirow[t]{2}{*}{ Number } & \multirow[t]{2}{*}{ Date } & \multirow[t]{2}{*}{ Time } & \multirow[t]{2}{*}{ Mag } & \multicolumn{2}{|c|}{ MYCR } & \multicolumn{2}{|c|}{ MYKO } & \multicolumn{2}{|c|}{ MYYA } & \multicolumn{2}{|c|}{ MYSA } & \multicolumn{2}{|c|}{ MIGA } \\
\hline & & & & $p_{o} ; \operatorname{amp}(\mathrm{Pa})$ & $\Delta t$; period (s) & $p_{o} ;$ amp (Pa) & $\Delta t$; period (s) & $p_{o} ; \operatorname{amp}(\mathrm{Pa})$ & $\Delta t$; period (s) & $p_{\mathrm{o}} ; \operatorname{amp}(\mathrm{Pa})$ & $\Delta t$; period (s) & $p_{o} ;$ amp $(\mathrm{Pa})$ & $\Delta t$; period (s) \\
\hline 1 & 29 October 2005 & $4: 32$ & 1.4 & 7.00 & 2.04 & 0.75 & 0.74 & 0.41 & 1.40 & 1.12 & 1.66 & 0.62 & 1.00 \\
\hline 2 & 30 November 2005 & $21: 35$ & 1.5 & & & & & 0.14 & 0.48 & & & & \\
\hline 3 & 30 November 2005 & $22: 55$ & 1.6 & 0.70 & 2.32 & & & & & & & 0.12 & 2.20 \\
\hline 4 & 29 December 2005 & 16.32 & 1.4 & 4.44 & 0.54 & & & 0.09 & 0.52 & 0.17 & 0.32 & 0.11 & 0.36 \\
\hline 5 & 17 February 2006 & 20:05 & 1.8 & 5.04 & 1.30 & & & 0.33 & 1.66 & & & & \\
\hline 6 & 17 February 2006 & $22: 37$ & 2.1 & 1.72 & 0.62 & & & & & & & & \\
\hline 7 & 17 February 2006 & $23: 33$ & 1.9 & 3.75 & 1.24 & 0.91 & 1.30 & 0.36 & 1.22 & & & 0.43 & 1.12 \\
\hline 8 & 22 March 2006 & $3: 15$ & 1.6 & 0.76 & 0.86 & & & & & & & & \\
\hline 9 & 23 April 2006 & 4:03 & 2.1 & 4.09 & 0.90 & & & 0.36 & 0.50 & 0.59 & 0.50 & 0.53 & 0.50 \\
\hline 10 & 21 May 2006 & $2: 06$ & 2.0 & & & & & & & 0.19 & 0.64 & & \\
\hline 11 & 21 May 2006 & 4:02 & 1.9 & & & & & & & & & 0.38 & 1.08 \\
\hline 12 & 29 June 2006 & 11:33 & 2.2 & 8.37 & 1.40 & 0.98 & 1.60 & 0.58 & 2.00 & & & 0.78 & 1.84 \\
\hline 13 & 23 August 2006 & $4: 24$ & 1.6 & 1.80 & 0.50 & 0.24 & 0.62 & 0.12 & 0.54 & 0.18 & 0.84 & & \\
\hline 14 & 23 August 2006 & $4: 25$ & 1.8 & 0.54 & 0.62 & & & & & & & & \\
\hline 15 & 23 August 2006 & $4: 44$ & 1.2 & 0.65 & 0.80 & 0.10 & 1.40 & 0.05 & 1.30 & 0.11 & 1.34 & 0.05 & 1.40 \\
\hline 16 & 23 August 2006 & $22: 38$ & 2.1 & 7.22 & 2.00 & 0.49 & 1.00 & 0.36 & 2.06 & 0.73 & 1.40 & 0.43 & 1.76 \\
\hline 17 & 28 August 2006 & 9:29 & 1.0 & & & & & 0.09 & 0.70 & & & & \\
\hline 18 & 5 October 2006 & $0: 26$ & 1.9 & & & & & 0.35 & 2.20 & & & 0.37 & 1.70 \\
\hline 19 & 5 November 2006 & $7: 46$ & 1.5 & & & & & 0.10 & 0.82 & & & & \\
\hline 20 & 5 November 2006 & $11: 55$ & 1.8 & & & 0.62 & 0.40 & 0.34 & 0.76 & & & 0.51 & 0.70 \\
\hline 21 & 17 February 2007 & 18:48 & 1.4 & & & & & 0.19 & 0.70 & & & & \\
\hline 22 & 11 April 2008 & 23:29 & 2.1 & & & & & & & 0.52 & 1.80 & 0.35 & 1.50 \\
\hline 23 & 8 May 2008 & $8: 22$ & 1.6 & & & & & 0.17 & 1.20 & & & 0.16 & 1.36 \\
\hline
\end{tabular}

amp, maximum amplitude (zero to peak) of the initial dilatational infrasonic pulse. period, the wave period which is referring to the timing of the maximum amplitude. 


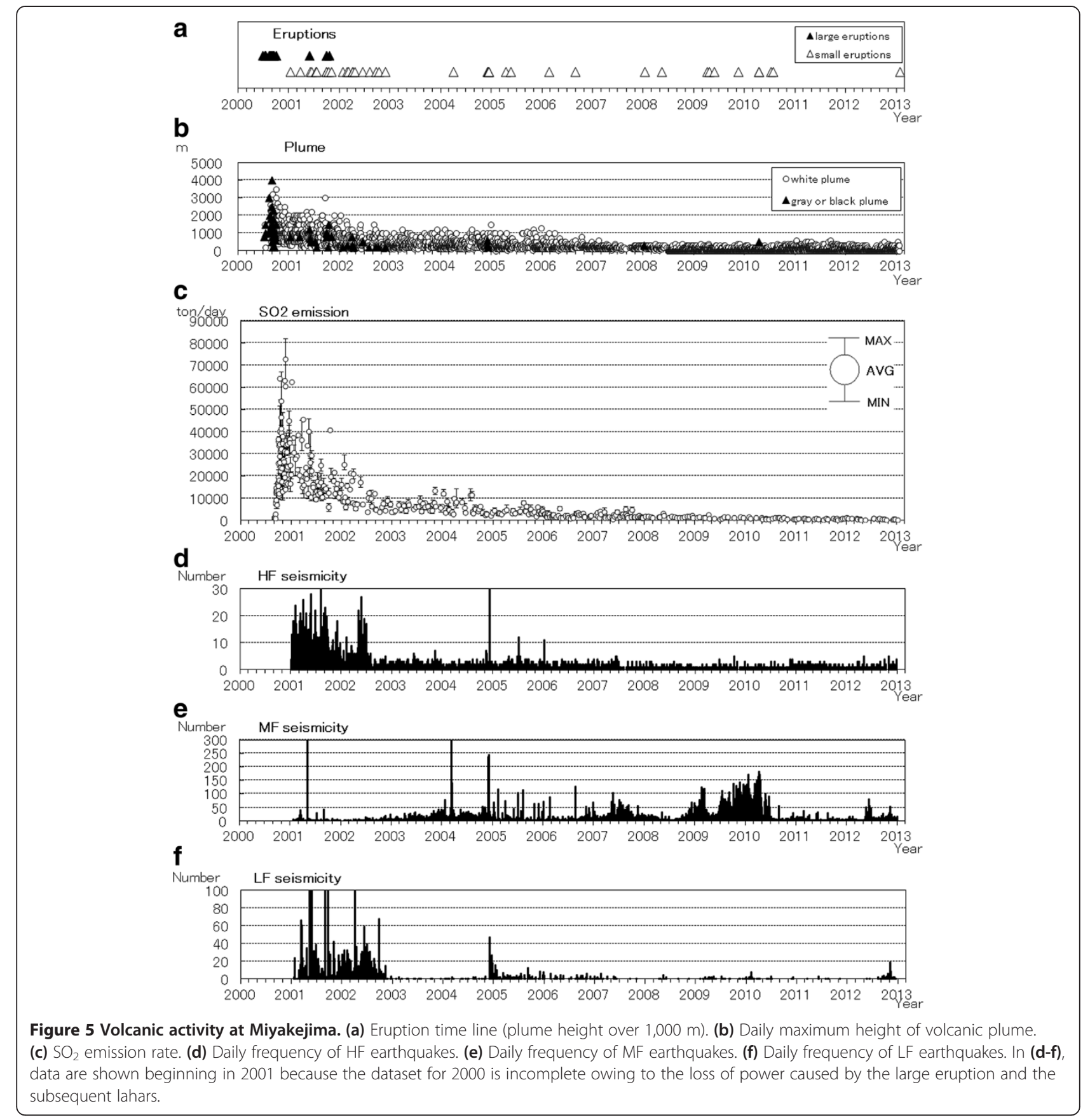

2003, when, conversely, an increase in MF earthquake frequency was observed. The most recent period (from December 2004) was characterized by another increase in the frequency of LF earthquakes, and this increase was linked to occasional swarms of MF earthquakes of very small magnitude.

\section{LF earthquake waveforms}

Typical LF seismic waveforms and waveforms of associated infrasonic pulses are shown in Figures 4, 6, and 7. Ground motion noise is sometimes superimposed on the infrasonic record (Figure 4) through the infrasonic pulse. Interestingly, at every station, LF earthquake waveforms generally contain an infrasonic wave whose first motion is dilatational and whose subsequent motion is compressional (Figures 4 and 7). The compressional amplitude, assumed to be generated by the emission of a certain amount of volcanic gas and/or volcanic ash, is larger than the first dilatational phase in some cases, which indicates that ash smoke is emitted incidentally. Also, that is supported by the fact that seismic amplitudes have no connection with the volume of emitted volcanic ash 


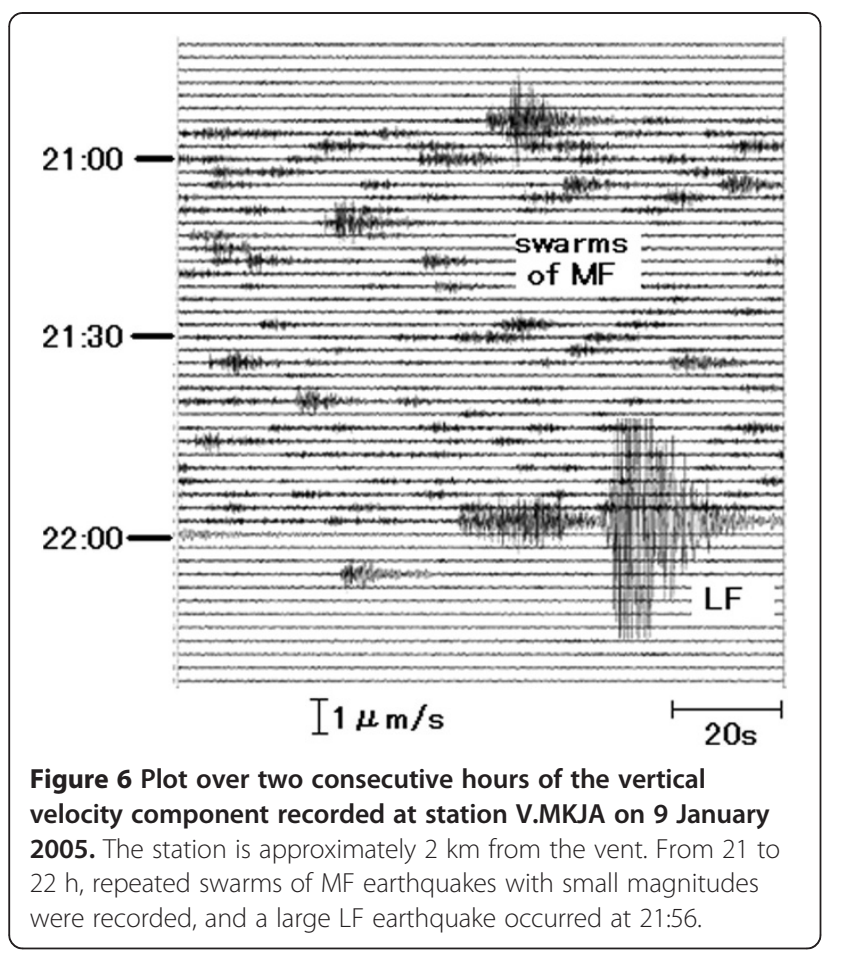

(see 'Results and discussion'). In some cases, clear dilatational polarity cannot be identified because the onset of the infrasonic wave is ambiguous, possibly owing to wind-induced noise or the original emergent source. As shown in Figure 8, the infrasonic pulse is apparently propagated through the atmosphere at the velocity of sound (approximately $340 \mathrm{~m} / \mathrm{s}$ ). On the other hand, the apparent seismic velocity is approximately $2.0 \mathrm{~km} / \mathrm{s}$ (Figure 8). This velocity is almost the same as the uppermost velocity structure (1.8 to $2.2 \mathrm{~km} / \mathrm{s})$ inferred from an artificial explosion experiment conducted by the Disaster Prevention Congress of the Tokyo Metropolitan Government (Disaster Prevention Congress 1990), and indicates that the source depth of the LF earthquakes is very shallow.

\section{Source location of the infrasonic pulses}

We computed the source locations of the infrasonic pulses associated with the larger LF seismic earthquakes (Table 1 ) by a method similar to that used by Yamasato (1997, 1998). Since the infrasonic pulses are strongly correlated among the stations, we assumed that an infrasonic pulse propagates uniformly through the atmosphere at the

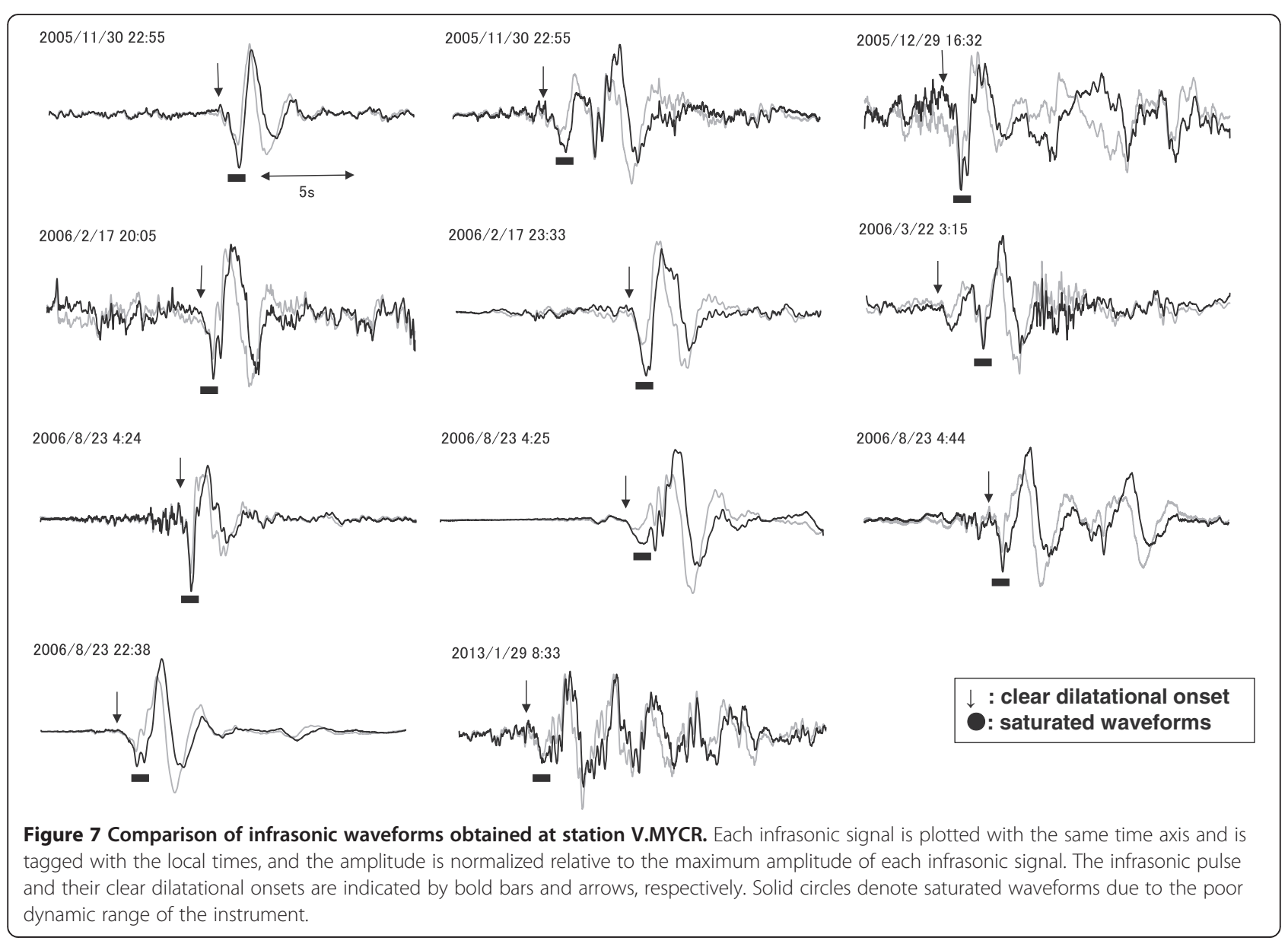



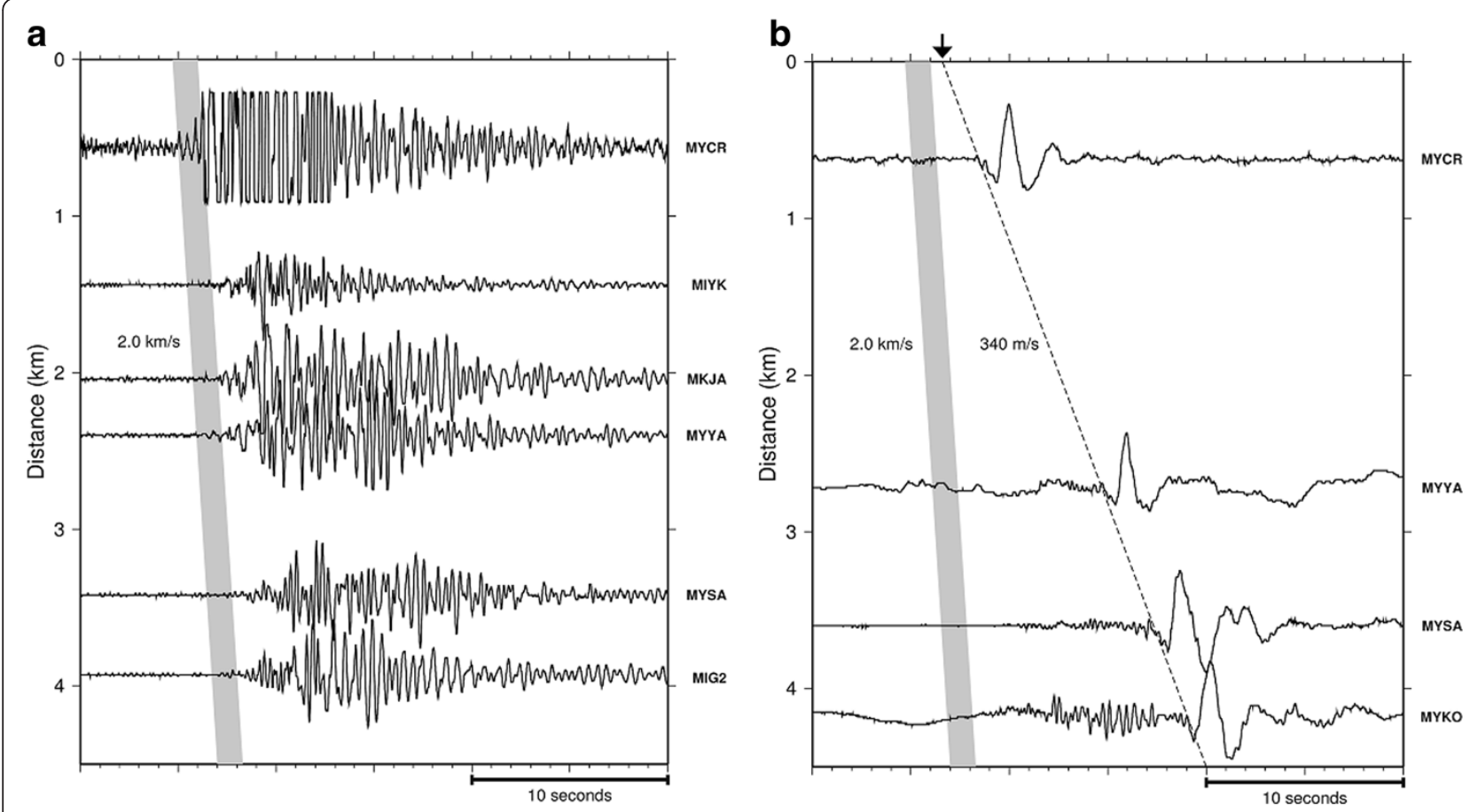

Figure 8 Seismic signals and corresponding infrasonic pulses. (a) Seismic signals for the LF earthquake recorded on 29 October 2005 at 04:32 local time. The shaded bar indicates the uncertain onset of the seismic waveform. All waveforms are normalized relative to the maximum amplitude. The vertical axis corresponds to the epicentral distance of the stations from the vent in the caldera. The apparent seismic wave velocity was approximately $2.0 \mathrm{~km} / \mathrm{s}$. (b) Corresponding infrasonic pulses for the same earthquake. The shaded bar is the same as in (a). Note that high-frequency noise due to ground motion is superimposed on the signal before the onset of the pulse. The oblique dashed line, which connects the onset of the infrasonic pulse at each station, shows that the mean velocity was approximately $340 \mathrm{~m} / \mathrm{s}$. The arrow indicates the time of infrasonic excitation indicated by the source calculation. In both (a) and (b), the distance from the main vent with the topographical correction is shown on the vertical axis. Station codes are shown to the right of the traces.

velocity of sound. To calculate the infrasonic sources, we introduced a topographical correction under the assumption that the infrasonic pulse travels between the sources and the receivers through the atmosphere over the caldera rim, as proposed by (Minakami et al. 1970) (Figure 9), and the differences in arrival times between the direct paths from the crater to each station and the ones which travel over the caldera rim are added as correction values for at least four stations, one of which was V.MYCR. In addition, all sources were fixed at the elevation of the caldera floor (300 $\mathrm{m}$ above sea level). Under these assumptions, we computed the source location of each earthquake with a relatively clear infrasonic pulse onset (Figure 7). The results (Figure 2) showed that the sources of all earthquakes were near the vent within the caldera. The error in all hypocenter locations is less than $50 \mathrm{~m}$. JMA (2011) reported that LF earthquakes occurred at $<1 \mathrm{~km}$ depth in the vent, so the source locations of both the infrasonic pulses and the LF earthquakes were almost the same. The use of primary infrasonic arrivals, however, allows a more precise estimation of the LF earthquake source locations. Conversely, although in most cases we cannot determine the epicenter of LF earthquakes precisely because these earthquakes often lack a clear seismic onset, from this analysis, we inferred that the LF sources were located just beneath the caldera floor.

\section{Results and discussion}

At Miyakejima, two types of earthquakes are accompanied by infrasonic waves: eruptions, which are associated with continuous tremors, and low-frequency (LF) earthquakes, which are accompanied by waves such as those described in the present study. We compared maximum amplitudes of seismic and infrasonic signals (Figure 10) using the vertical component at V.MYSA station for the maximum seismic amplitude, because there were gaps in the data at other stations due to instrument failure. The seismic signal of some of the larger LF earthquakes was saturated because of the narrow dynamic range of the seismometer, so we corrected the amplitude of those seismic signals at V.MYSA from the record at MIYKE by geometrical spreading relationship. For the infrasonic signal, we assumed that the infrasonic pulse attenuates with $1 / r$, where $r$ is the distance between the source and the station, and used the averaged amplitudes of the four stations at the foot of Miyakejima. 


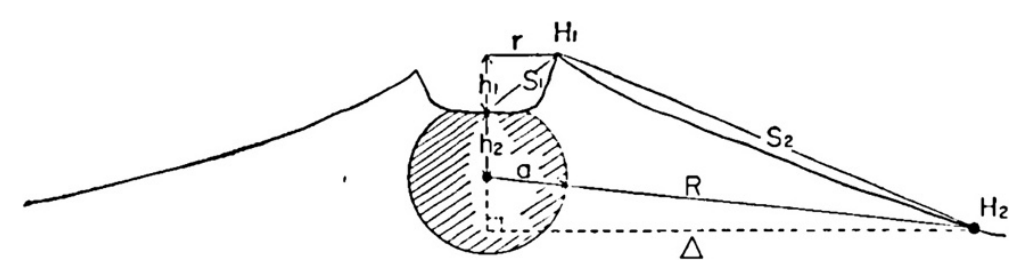

Figure 9 A model showing the raypath between source and station (Minakami et al. 1970). $H_{1}$, elevation at the caldera margin; $H_{2}$, station elevation; $S_{1}+S_{2}$, distance along the Earth's surface to the station; $h_{1}$, caldera depth; $h_{2}$, hypocentral depth measured from the caldera floor; $a$, radius of the spherical hypocenter domain (in this paper, $a=0, h_{2}=0$, under the assumption that the infrasonic signal is excited at the floor of the caldera); $r$, horizontal distance from the caldera margin to the source; $\Delta$, epicentral or horizontal distance from the hypocentral domain to the station. The corrected distance $S_{1}+S_{2}-R$ is calculated for each station.

In most cases, infrasonic signals are generally understood to be excited by volcanic eruptions. The plots of maximum amplitudes (Figure 10) could be divided into two groups, A and B. Group A consisted of the remarkable eruption events in August 2000 and several LF earthquakes, but most LF earthquakes were included in group B. Most group A earthquakes ejected volcanic ash, suggesting that the triggering mechanism of the infrasonic pulses was tremors or earthquakes associated with the abrupt underground movement of volcanic gas and fluid during eruptions or ash explosions; as pointed

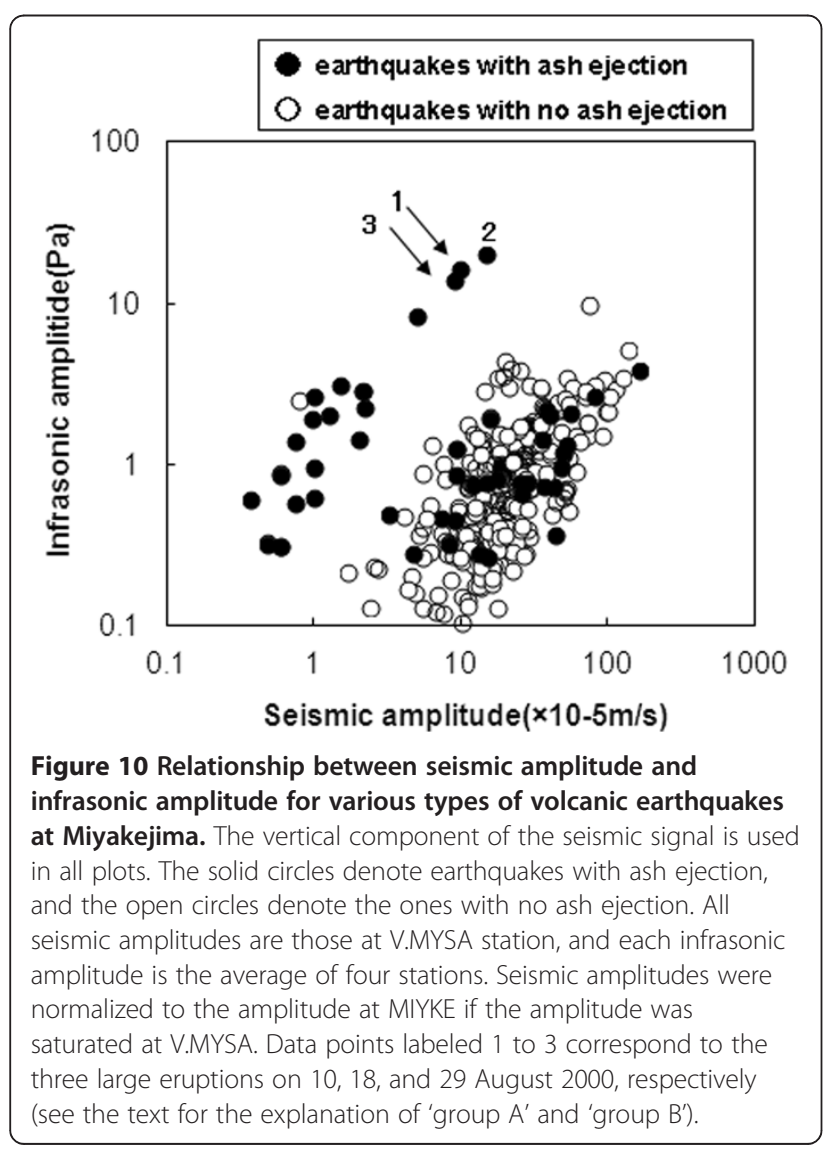

out by Ishihara and Iguchi (1989), this phenomenon is commonly observed at other active volcanoes. At Miyakejima, eruptive tremors are included in group A, indicating that the seismic-infrasonic amplitude relationship of group A is consistent with that of other volcanoes (Yamasato et al. 2008). However, the maximum infrasonic amplitude of the earthquakes in group B was significantly smaller relative to the maximum seismic amplitude compared with that in group A, which suggests that the group B mechanism was different from that observed at other active volcanoes.

The main characteristics of group B earthquakes are as follows: (1) The low apparent velocities of the LF earthquakes indicate that they occur at a very shallow depth beneath the vent in the caldera (see Figure 2). (2) The LF earthquakes are accompanied by emergent infrasonic pulses starting with a dilatational phase. (3) The infrasonic waves from LF are much smaller than those associated with eruptions.

These findings indicate that the LF earthquakes in group B cannot be explained by explosive or other eruptions. At Miyakejima Volcano, very-long-period (VLP) earthquakes were observed during the caldera formation. Kumagai et al. (2001) revealed that VLP seismic signals can be explained by piston-like subsidence in the conduit and magma chamber related to caldera formation. Yamamoto (2003) reported that a change of air pressure was observed immediately after the gradual formation of the caldera in the air pressure records of instruments deployed at Miyakejima. Even now, although caldera formation at Miyakejima has ceased, partial subsidence of the vent in the caldera since 2002 has been observed by remote sensing analysis (H. Yarai, personal communication, 2008). Therefore, it is possible that the dilatational infrasonic pulse is excited by such subsidence. Because the infrasonic sources were distributed at the vent within the caldera, we inferred that subsidence was occurring in the shallow part of the conduit. We tried to calculate the subsidence volume for each LF earthquake from the infrasonic records. The characteristics of an 

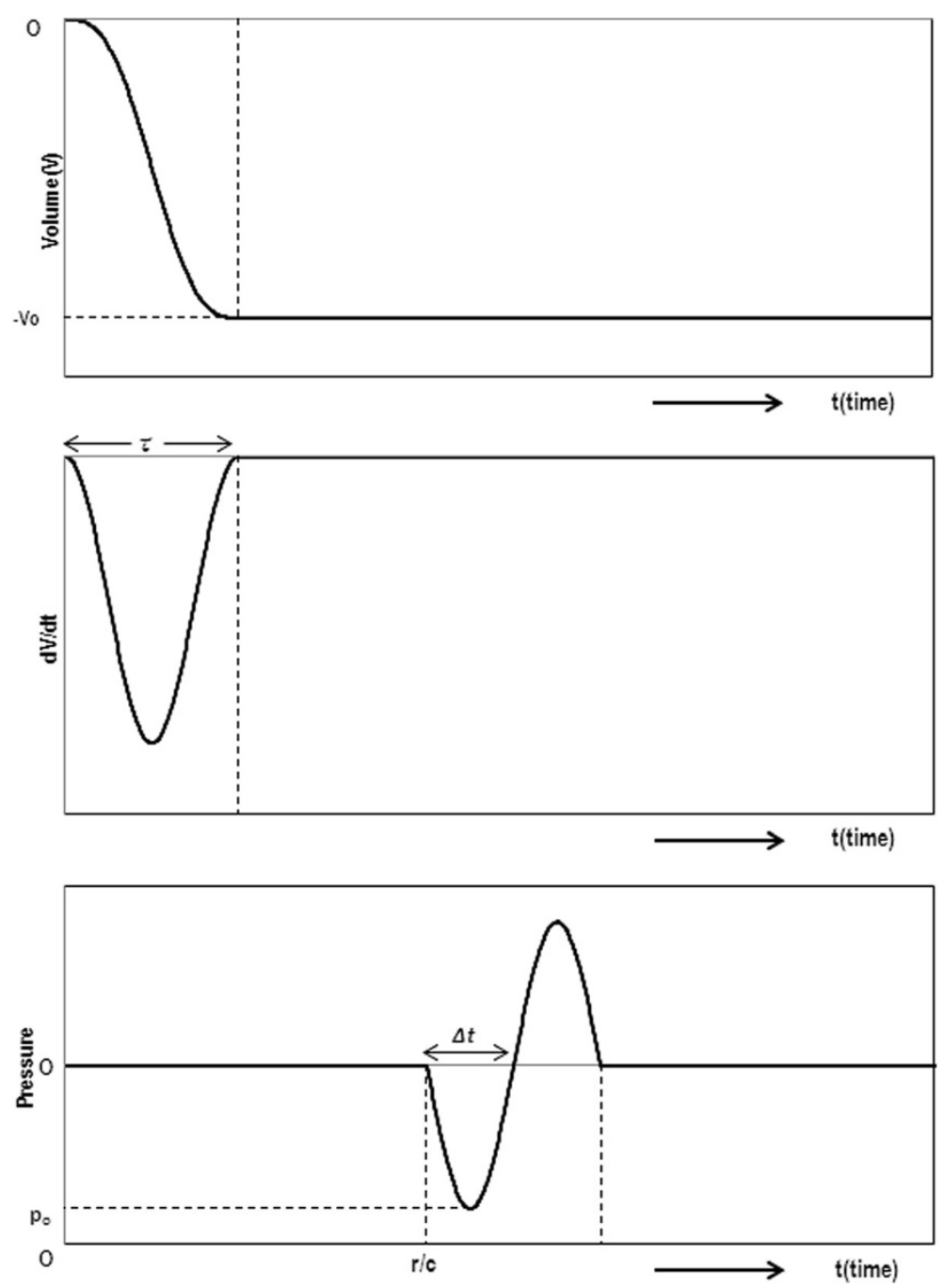

Figure 11 Diagram showing volumetric change due to subsidence within the vent associated with LF earthquakes (after Yamasato (1998)).

infrasonic wave induced by a small volumetric change at the ground surface are given by Yamasato (1998) and shown in Figure 11:

$$
V=\frac{r\left|p_{o}\right|}{\rho} \tau^{2}=\frac{4 r\left|p_{o}\right|}{\rho} \Delta t^{2}
$$

where $r$ is the distance from the source to the receiver, $\rho$ is the density of the air, $p_{\mathrm{o}}$ is the maximum negative amplitude of the rarefaction phase, $\tau$ is the rise time of the downlift, and $\Delta t$ is the pulse width. The location of all sources was assumed to be at the center of the vent. If we assign the following parameter values, $\rho=1.2 \mathrm{~kg} / \mathrm{m}^{3}$, $\Delta t=0.2$ to $2.0 \mathrm{~s}, p_{\mathrm{o}}=0.1$ to $10 \mathrm{~Pa}$, and $r=600 \mathrm{~m}$ (V.MYCR) from the data shown in Table 1 , we obtain a plausible estimate of the subsidence volume of $0.1 \times 10^{3}$ to $100 \times 10^{3} \mathrm{~m}^{3}$. In some cases, LF accompanies very small eruptions. Because the eruptions are small, the volume of ash from each eruption is usually too small to estimate, but H. Shinohara (AIST; Advanced Industrial Science and Technology; personal communication, 2005) calculated an ash weight of $4 \times 10^{6} \mathrm{~kg}$ for one of the largest eruptions, which occurred on 2 December 2004. As this eruption occurred at the same time as several LF events, the ash volume emitted per eruption since 2005 must be much lower. Therefore, the estimated subsidence volume must be significantly larger than the ash volume, and we can deduce that LF earthquakes trigger partial subsidence having a volume of $0.1 \times 10^{3}$ to $100 \times 10^{3} \mathrm{~m}^{3}$ within the conduit and may, incidentally, induce emissions of small amounts of ash. On this basis, we therefore propose a model to explain our observations, in which the LF earthquakes and infrasonic pulses are interpreted as originating from partial subsidence 


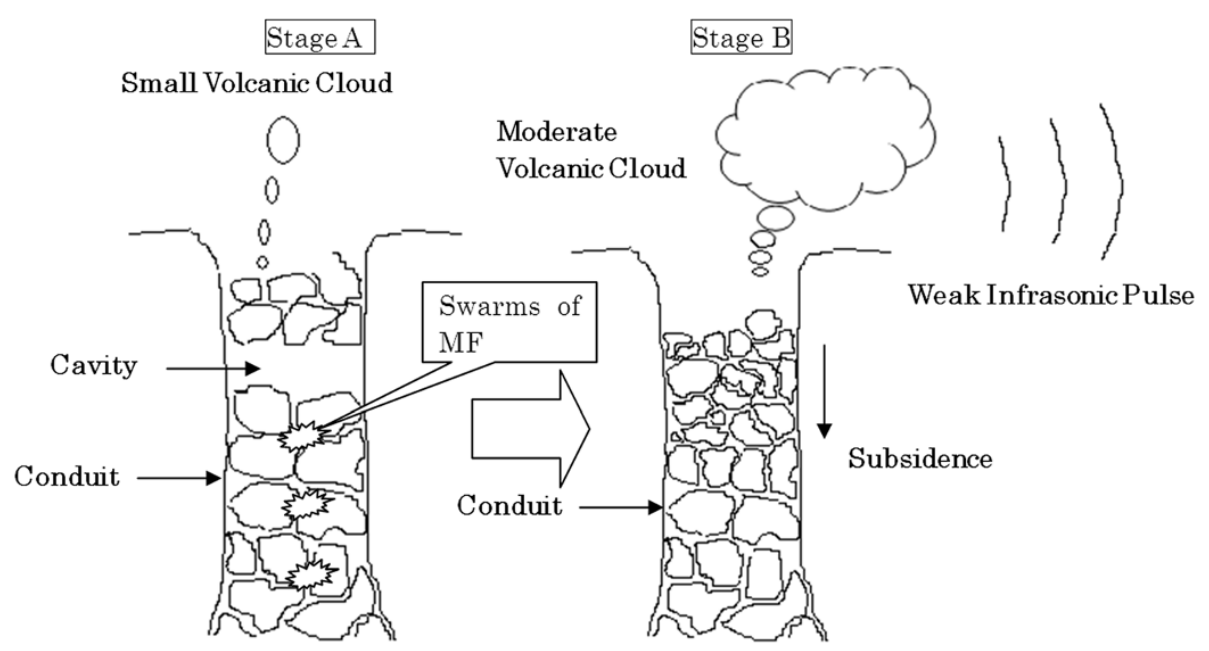

Figure $12 \mathrm{~A}$ model showing the structure beneath the main vent before (A) and after (B) an LF earthquake.

in the conduit beneath the vent within the caldera, as illustrated in Figure 12.

At stage A, a cavity has developed within the conduit, perhaps because of magma withdrawal in the conduit, which is controlled by the conditions below ground. Swarms of MF earthquakes which are observed in the shallow part of the conduit may be related to instability of the rocks within the vent, perhaps caused by the presence of a cavity; thus, they can be precursors to LF earthquakes. At stage B, larger magnitude LF earthquakes occur, perhaps triggered by many MF earthquakes, leading to the partial subsidence of the rocks in the conduit. In some cases, a small amount of ash smoke is also emitted incidentally, which indicates that seismic amplitudes have no connection with the volume of emitted volcanic ash. Simultaneously, the small volumetric change due to the subsidence is converted to a weak infrasonic pulse, which travels through the atmosphere from the vent to each station. This interpretation is very simple and straightforward, but we believe that it has first-order plausibility. At present, no clear evidence from visual or other observations supports the inference of partial subsidence in the conduit, which may indicate that the subsidence associated with LF earthquakes is too small to be detected by our observations. Precise geodetic observations need to be obtained by instruments such as tiltmeters, which should be deployed in the caldera in the vicinity of the vent to clarify the mechanism of LF earthquakes and infrasonic waves.

\section{Conclusions}

The LF earthquakes at Miyakejima can be characterized as follows: LF earthquakes occasionally occur after MF microearthquake swarms. Some LF earthquakes are accompanied by dilatational infrasonic signals with weak onsets. The time lapses between the seismic signals and the infrasonic pulses indicate that the earthquakes are related to partial subsidence in the conduit beneath the vent. These observations are supported by the rough relationship between the amplitudes of the infrasonic and seismic signals. Moreover, the subsidence volume calculated from each infrasonic pulse is roughly consistent with the quantity of volcanic ash emitted during minor eruptions associated with LF earthquakes at Miyakejima.

\section{Competing interests}

The authors declare that they have no competing interests.

\section{Authors' contributions}

YF and HY designed the research, and YF wrote the paper and conducted the analysis. HY participated in the design of the study and contributed in the revision of the whole manuscript. Tos carried out phase response and corrected waveform for the original infrasonic waveform and participated in the sequence alignment. TaS participated in its design and coordination and helped to check the manuscript in detail. All authors read and approved the final manuscript.

\section{Author details}

'Japan Meteorological Agency, 1-3-4 Otemachi, Chiyoda-ku, Tokyo 100-8122, Japan. ${ }^{2}$ Kagoshima Local Meteorological Observatory, Japan Meteorological Agency, Kagoshima 890-0068, Japan. ${ }^{3}$ Meteorological Research Institute, Japan Meteorological Agency, Nagamine 1-1, Tsukuba, Ibaraki 305-0052, Japan.

Received: 10 April 2012 Accepted: 25 November 2013 Published: 16 April 2014

\section{References}

Disaster Prevention Congress (1990) Report on the characteristics of volcanic eruptions in the Izu Islands. Tokyo Metropolitan Government, p 103

Ishihara K, Iguchi M (1989) The relationship between microearthquake swarms and volcanic activity at Sakurajima Volcano, vol 32B-1. Kyoto University, Disaster Prevention Research Institute, Annual Report, pp 1-11

JMA (2011) Volcanic activity of Miyakejima (from October to December 2009). Rep Coord Committee Prediction 105:107-117

Kamo K, Ishihara K, Tahira M (1989) Infrasonic and seismic detection of explosive eruptions at Sakurajima Volcano, Japan, and the PEGASAS-VE early warning system. U.S. Geol Surv Bull 2047:357-365 
Kazahaya K, Shinohara H, Uto K, Odai M, Nalkahori Y, Mori H, lino H, Miyashita M, Hirabayashi J (2004) Gigantic $\mathrm{SO}_{2}$ emission from Miyakejima Volcano, Japan, caused by caldera collapse. Geology 32(5):425-428

Kumagai H, Ohminato T, Nakano M, Ooi M, Kubo A, Inoue H, Oikawa J (2001) Very-long-period seismic signals and caldera formation at Miyake Island, Japan. Science 293:687-690

Minakami T, Utibori S, Hiraga S, Miyazaki T, Gyoda N, Utsunomiya T (1970) Seismometrical studies of volcano Asama. Part 1. Bull Earthquake Res Inst 48:235-301

Nakada S, Nagai M, Kaneko T, Nozawa A, Suzuki-Kamata K (2005) Chronology and products of the 2000 eruption of Miyakejima Volcano, Japan. Bull Volcanol 67:219-230

Okada H, Nishimura Y, Miyamachi H, Mori H, Ishihara K, Iguchi M (1990) Geophysical significance of the 1988-1989 explosive eruptions of Mt. Tokachi, Hokkaido, Japan. Bull Volcanol Soc Japan Ser 2(35):175-203

Sakai T, Yamasato H, Uhira K (1996) Infrasound accompanying C-type tremor at Sakurajima Volcano. Bull Volcanol Soc Japan Ser 2(41):181-185, in Japanese

Shimbori T, Kokubo K, Takagi A, Onizawa S, Yamamoto T, Fukui K, Ando S, Fujiwara Y, Sakai T, Yamasato H, Ueda Y, Kato K, Nakahashi M, Matsusue S (2013) Intercomparison observation of the infrasound at Sakurajima Volcano. Japan Geoscience Union Meeting, MTT40-P02, Chiba, Japan

Tsukui M, Suzuki Y (1998) Eruptive history of Miyakejima Volcano during the last 7000 years. Bull Volcanol Soc Jpn 43:149-166, in Japanese

Tsukui M, Niihori K, Kawanabe Y, Suzuki Y (2001) Stratigraphy and formation of Miyakejima Volcano. J Geogr 110:156-167 (in Japanese)

Uhira K, Baba T, Mori H, Katayama H, Hamada N (2005) Earthquake swarms preceding the 2000 eruption of Miyakejima Volcano. Bull Volcanol 67:219-230

Yamamoto E (2003) Caldera forming detected barometric observation at Miyakejima Volcano. NIED News 144:2-3 (in Japanese)

Yamasato H (1997) Quantitative analysis of pyroclastic flows. J Phys Earth 45:397-416

Yamasato H (1998) Nature of infrasonic pulse accompanying low frequency earthquake at Unzen Volcano, Japan. Bull Volcanol Soc Japan 43:1-13

Yamasato H, Fujita E, Ukawa M, Miyamura J, Kato K, Takagi A (2008) Characteristics of low frequency earthquakes beneath the summit caldera of Miyakejima Volcano, Japan. 7th General Assembly of Asian Seismological Commission and Seismological Society of Japan. Fall meeting, Tsukuba, Japan Yamasato H, Miyamura J, Mori H, Usui Y, Sakuma K, Watanabe A, Sato J, Takahashi Y, Sakai T (2002) Eruptive activity inferred from infrasound associated with the 2000 eruption of Usu Volcano. Bull Volcanol Soc Jpn 47:255-262, in Japanese

doi:10.1186/1880-5981-66-11

Cite this article as: Fujiwara et al:: Characteristics of dilatational infrasonic pulses accompanying low-frequency earthquakes at Miyakejima Volcano, Japan. Earth, Planets and Space 2014 66:11.

\section{Submit your manuscript to a SpringerOpen ${ }^{\circ}$ journal and benefit from:}

- Convenient online submission

- Rigorous peer review

- Immediate publication on acceptance

- Open access: articles freely available online

- High visibility within the field

- Retaining the copyright to your article

Submit your next manuscript at $>$ springeropen.com 